\title{
COOPERATIVE R\&D CONTRACT OF SUPPLY CHAIN CONSIDERING THE QUALITY OF PRODUCT INNOVATION
}

\author{
Wu, S. B. ; Gu, X.**\#; Wu, G. D. ${ }^{* * *} \&$ Zhou, Q. \\ ${ }^{*}$ Chongqing Technology and Business University, Chongqing 400067, China \\ ${ }^{* *}$ Sichuan University, Chengdu 610064, China \\ *** Jiangxi University of Finance \& Economics, Nanchang 330013, China \\ E-Mail: gx6664@sina.com (" Corresponding author)
}

\begin{abstract}
This paper researches the conditions where the manufacturer focuses on development of core components and outsources development of supporting components to the supplier in the collaborative $\mathrm{R} \& \mathrm{D}$ of the supply chain. The manufacturer needs to consider the impact on market revenue of innovation quality when they design contracts in order to avoid unethical behaviour of suppliers. The manufacturer should not only offer the suppliers a certain fixed payment, but also share the market revenue from the products with the suppliers. This study research arrives at several conclusions. First, the optimal revenue sharing coefficient has a negative correlation with the impacting coefficient of the success of product innovation, which is affected by the efforts put into core components development by the manufacturer. Second, the optimal revenue sharing coefficient has a positive correlation with the impacting coefficient of the success of product innovation success, which is affected by the efforts put in development of supporting component by the supplier. Third, the optimal revenue sharing coefficient has no correlation with the fixed payment and innovation quality of product. Fourth, the optimal fixed payment has positive correlation with the cost coefficient of developing the core components and supporting component by both sides in the supply chain, and it has negative correlation with innovation quality of products.

(Received, processed and accepted by the Chinese Representative Office.)
\end{abstract}

Key Words: Supply Chain, Collaborative R\&D, Innovation Quality of Products, Contract

\section{INTRODUCTION}

With the continuous development of science and rapid globalization, enterprises must concentrate on key businesses which can create core values due to intensified competition, while at the same time, adopting methods of outsourcing the non-core businesses so as to respond to the market demand quickly and take advantage of market opportunities in advance $[1,2]$. In the supply chain, the core enterprise only works on the core component development at any given time, entrusting the work of supporting component development to outside suppliers. In this way, manufacturers and suppliers may accelerate the process of product development while realizing collaborative innovation in the supply chain. Many well-known international manufacturing enterprises, such as HP in the IT industry, and Ford and Chrysler in the automobile industry, utilize concurrent engineering (CE) in the area of new product development. Among them, Ford and Chrysler make their own major suppliers comprehensively participate in the innovation processes by using the $\mathrm{C} 3 \mathrm{P}$ system or implementing the SCORE plan. Thus, collaborative innovation in the supply chain has become the main approach of innovating among enterprises. (Alshawi et al., Milliou, Morgan \& Liker, Olausson et al., Tsai) [3-7]. According to the research of Rokuhara, $90 \%$ of collaborative innovations among enterprises in the supply chain are cross-industrial collaboration [8]. Harabi analyses data in Germany from 1994 and reveals that $84 \%$ of emerging enterprises collaborated with clients and/or suppliers for R\&D [9]. Licht and Zoz investigate enterprises' collaborative $R \& D$ in six European countries and finds that 
collaborating with clients and/or suppliers is the most widespread approach for collaborative R\&D of enterprises [10].

Scholars ouside of China researches the driving factors, collaboration modes, benefits distribution and contracts design of $R \& D$ outsourcing in collaborative innovation in the supply chain by using methods of enterprise survey, case study and empirical analysis. Mikkola and Skjoett-Larsen consider that the major motivations for suppliers' participation in collaborative innovation in the supply chain include promoting fast development of technology, shortening product life cycle, heightening competition, increasing outsourcing, improving the efficiency and effect of product development, as well as introducing the technological capabilities of suppliers [11]. Atallah considers the situations such as non-cooperation of enterprises of upper lower reaches $R \& D$ activities, the simultaneous horizontal collaborations within industry, vertical collaboration in the supply chain's upper and lower reaches, as well as the common collaborations among enterprises in the supply chain. This research studies the impacts on R\&D investment of enterprises, product output, profits and social welfare made by vertical spillover across industries and horizontal spillover within an industry. The research discovers that vertical spillover always increases R\&D investment, while horizontal spillover has an uncertain impact [12]. Petersen et al. expounds the long-term collaborative relationship among supply chain members, and points out that the vertical supply chain gains more advantages than horizontal alliance of enterprises in the aspect of collaborative product innovation, which is effective because it improves the product innovation revenue of both the supply chain members and the whole supply chain simultaneously [13]. Gilbert and Cvsa constructs models to analyse the innovative function of stimulus on the lower reach of the supply chain caused by the suppliers' strategic commitment of price [14]. By adopting multiple case study methods, Van Echtelt et al. analyse impacts on the performance of collaborative product innovation, which are made by member enterprises having similar strategic aims in the supply chain, and concludes that the more significant assimilation of member enterprises' strategic aims, the closer relationship among them, resulting in more positive impacts on the performance of collaborative product innovation [15]. Lakemond et al. divides the suppliers' participative collaboration into three categories: participation based on project, direct and special collaboration and participation in subprojects incoherently. These three kinds of collaborative approaches determine the evolving trends in their own dominated innovation platform [16]. Çanakoğlu and Bilgic studies the revenue distribution mechanism of the supply chain system of wireless telecommunication with independent technical requirements, and argues that the collaborative members distribute revenue in accordance with technology input rate, and in this way arrive at the Nash equilibrium solution of revenue distribution [17]. Jean et al. [18] investigate 170 transnational suppliers of automobile components in China, empirically analysing the impacts of collaborative product innovation in the supply chain, which are affected by suppliers participating and other factors, as well as the impacts of knowledge barriers, trust or mistrust, uncertainty of technology, and enterprises' external system environment. Kim and Lim consider the R\&D outsourcing issues in the supply chain driven by innovation, and finds that enterprises are more willing to outsource their $R \& D$ through $R \& D$ racing when the enterprises' $R \& D$ cost is higher than a certain threshold. Their research shows that enterprises can benefit from $R \& D$ outsourcing when inviting more firms to participate in $R \& D$ racing [19]. Wang and Shin research the impacts of the supply chain contract and endogenous innovation, putting emphasis on three kinds of different contract solutions: wholesale price contract, wholesale price contract related to quality, and revenue sharing contract. Their study shows that a revenue sharing contract can coordinate supply chain decisions including the amount of investment in innovation. And other two kinds of contracts may lead to insufficient investment, thus negatively influencing innovation [20]. It can be inferred that the previous 
literature on collaborative innovation in the supply chain does not consider the impacts on contract designing of the quality of product innovation in the process of $R \& D$ outsourcing in the supply chain. Therefore, this research can fill in the gaps of existing theories.

This paper considers the following situations of product innovation. When the manufacturer develops a product, the product consists of one core component and one supporting component. In the supply chain, the manufacturer (i.e., core enterprise) itself only engages in core component development, outsources the job of developing matching products to a supplier, and in the end is responsible for selling the product after the successful development of the whole product. When designing the contract, if the manufacturer offers the supplier only a fixed payment, the manufacturer may be vulnerable to unethical behaviour on the part of the supplier in the process of outsourcing the job of developing supporting components. Supplier's potential unethical behaviour is made possible by the fact that the task (effort) of the development of supporting components, which is determined (input) by the supplier, is unobservable. Therefore, the manufacturer must consider the quality of product innovation when it designs a contract with the supplier. For the mutual benefit of both the supplier and manufacturer and to reduce the risk of unethical behaviour on the part of the supplier, the manufacturer must share with the supplier the market revenue from sales of the product to lower the quality risk of outsourcing development of supporting components. During the process of product development, the manufacturer initially gives the supplier a payment of a fixed amount for development of supporting components. Then the manufacturer claims that the fixed amount payment should be reduced as much as possible while market revenue from the product is increased the competitive marketing process in order to lower the risks on each side, while the supplier asks for increasing the fixed payment rate while decreasing the market revenue rate. The two sides need a balance in the marketing process. This paper's structure is as follows. The first section is model hypothesis. The second section is model construction. The third section is model solving. The fourth section is analysis of the attributes of contract parameters. The fifth section is a calculation example and simulation analysis with the tool of MATLAB for verifying the theoretical analysis. The last section is the conclusion.

\section{MODEL ASSUMPTIONS}

The following assumptions are made in order to facilitate the research.

(1) The success probability of product development by the manufacturer and supplier is affected by their common input in the product development process. The manufacturer's and supplier's input effort of core component and supporting component is denoted as $e_{r}$, $e_{d}\left(0 \leq e_{r} \leq 1,0 \leq e_{d} \leq 1\right)$; the successful probability of product innovation is $\rho\left(e_{r}, e_{d}\right)=e_{r}^{\alpha} e_{d}^{\beta}, \alpha$; $\beta$ denotes the influence coefficient of core component and supporting component's input effort, and $0 \leq \alpha, \beta \leq 1$. At the same time, the probability function of successful product innovation meets the conditions:

$$
\frac{\partial \rho\left(e_{r}, e_{d}\right)}{\partial \alpha}>0, \frac{\partial^{2} \rho\left(e_{r}, e_{d}\right)}{\partial \alpha^{2}}<0, \frac{\partial \rho\left(e_{r}, e_{d}\right)}{\partial \beta}>0, \frac{\partial^{2} \rho\left(e_{r}, e_{d}\right)}{\partial \beta^{2}}<0 .
$$

These conditions mean that the more input effort of both the manufacturer and supplier, the possibility of successful product innovation is greater, and that the marginal effect of input effort is diminishing.

(2) The manufacturer's cost function of developing core component is $\lambda_{r} e_{r}^{2}, \lambda_{r}$ denotes the manufacturer's cost coefficient of developing core component and $\lambda_{r}>0$; the supplier's cost function of developing supporting component is $\lambda_{d} e_{d}^{2}, \lambda_{d}$ denotes the supplier's cost coefficient of developing supporting component and $\lambda_{d}>0$. 
(3) After the success of product innovation, the market demand is related to the quality of product innovation, denoted as $q(0<q<1)$; the greater the $q$, the higher the quality of product innovation, and the market sales revenue is higher; the market sales revenue is denoted as $\kappa q$ $(\kappa>0)$, where $\kappa$ denotes the market sales revenue of one unit of product innovation quality.

(4) The fixed payment the manufacturer pays to the supplier is $B(B>0)$ at the beginning of the product innovation. The manufacturer is responsible for product sales after the product innovation's success. The manufacturer and the supplier share the market sale revenue, and the supplier's share proportion is $\gamma(0 \leq \gamma \leq 1)$.

\section{MODEL CONSTRUCTION}

The collaborative product innovation of the supply chain is a three-stage process. At the first stage, the manufacturer designs the contract for outsourcing the supporting component development specifying the amount of the fixed payment and the revenue sharing ratio. At the second stage, the manufacturer cooperates with the supplier to develop the product, where the manufacturer is responsible for the development of the core component, and the supplier is responsible for the development of the supporting components. At the third stage, the manufacturer is responsible for market sales. We can get the manufacturer's and the supplier's market sales revenue obtained through a reverse solving method:

$$
\begin{gathered}
\pi_{r}=(1-\gamma) \kappa q \\
\pi_{d}=\gamma \kappa q
\end{gathered}
$$

So the supplier's expected revenue for engaging in supporting component's development is as follows:

$$
E\left(R_{d}\right)=B+\gamma \kappa q e_{r}^{\alpha} e_{d}^{\beta}-\lambda_{d} e_{d}^{2}
$$

The manufacturer's expected revenue for engaging in core component's development is as follows:

$$
E\left(R_{r}\right)=(1-\gamma) \kappa q e_{r}^{\alpha} e_{d}^{\beta}-B-\lambda_{r} e_{r}^{2}
$$

The manufacturer and the supplier select the input effort level to maximize their own revenue at the second stage, which is the product innovation stage.

The supplier selects its optimal input effort $e_{d}$ to maximize its revenue. By making the value of $e_{d}$ in Eq. (3) equal to zero, then the first optimal order condition is obtained as follows:

$$
\gamma \beta \kappa q e_{r}^{\alpha} e_{d}^{\beta-1}-2 \lambda_{d} e_{d}=0
$$

The manufacturer selects its optimal input effort $e_{r}$ to maximize its revenue. By making the value of $e_{r}$ in Eq. (4) equal to zero, then the first optimal order condition is obtained as follows:

$$
(1-\gamma) \alpha \kappa q e_{r}^{\alpha-1} e_{d}^{\beta}-2 \lambda_{r} e_{r}=0
$$

At the first marketing, the optimization problem of the contract can be described using the following model:

$$
\begin{gathered}
P 1 \max _{B, \gamma, e_{r}, e_{d}}(1-\gamma) \kappa q e_{r}^{\alpha} e_{d}^{\beta}-B-\lambda_{r} e_{r}^{2} \\
\text { S.T. }(1-\gamma) \alpha \kappa q e_{r}^{\alpha-1} e_{d}^{\beta}-2 \lambda_{r} e_{r}=0 \\
\gamma \beta \kappa q e_{r}^{\alpha} e_{d}^{\beta-1}-2 \lambda_{d} e_{d}=0
\end{gathered}
$$




$$
B+\gamma \kappa q e_{r}^{\alpha} e_{d}^{\beta}-\lambda_{d} e_{d}^{2} \geq U
$$

Expression (7) is the objective function; Eqs. (6) and (5) are the manufacturer's and the supplier's incentive compatibility constraints respectively; Eq. (8) is the constraint condition; $U$ is the supplier's reservation utility.

\section{MODEL SOLVING}

In Eq. (8), as long as the payment's utility that the manufacturer gives to the supplier equals to the supplier's reservation utility, the supplier will be involved in the development of supporting component. So, Eq. (8) holds equally on the optimal condition, and can be rewritten as follows:

$$
B=U-\gamma \kappa q e_{r}^{\alpha} e_{d}^{\beta}+\lambda_{d} e_{d}^{2}
$$

Eq. (9) is substituted into the objective function (7), Eq. (6) multiplies $e_{r}$ on both sides at the same time; Eq. (5) multiplies $e_{d}$ on both sides at the same time, and optimization problems P1 can be translated into the following optimization expressions:

$$
\begin{gathered}
P 2 \max _{\gamma, e_{r}, e_{d}} \kappa q e_{r}^{\alpha} e_{d}^{\beta}-\lambda_{r} e_{r}^{2}-\lambda_{d} e_{d}^{2}-U \\
\text { S.T. } \quad(1-\gamma) \alpha \kappa q e_{r}^{\alpha} e_{d}^{\beta}-2 \lambda_{r} e_{r}^{2}=0 \\
\gamma \beta \kappa q e_{r}^{\alpha} e_{d}^{\beta}-2 \lambda_{d} e_{d}^{2}=0
\end{gathered}
$$

Optimization problem P2 can be solved by the Lagrange method, the function of which is established as follows:

$$
\begin{aligned}
& L=\kappa q e_{r}^{\alpha} e_{d}^{\beta}-\lambda_{r} e_{r}^{2}-\lambda_{d} e_{d}^{2}-U+\phi\left[(1-\gamma) \alpha \kappa q e_{r}^{\alpha} e_{d}^{\beta}-2 \lambda_{r} e_{r}^{2}\right] \\
& +\varphi\left[\gamma \beta \kappa q e_{r}^{\alpha} e_{d}^{\beta}-2 \lambda_{d} e_{d}^{2}\right]
\end{aligned}
$$

By solving Eq. (13) the optimal revenue sharing coefficient is obtained as follows:

$$
\gamma^{*}=\frac{1}{1+\sqrt{\alpha(2-\beta) / \beta(2-\alpha)}}
$$

By substituting $\gamma^{*}$ into Eqs. (5) and (6) and solving it simultaneously, then the optimization input efforts of the manufacturer and the supplier are obtained as follows:

$$
\begin{gathered}
e_{r}^{*}=\exp \left[\frac{(2-\beta) \ln \left(\frac{\kappa q \alpha\left(1-\gamma^{*}\right)}{2 \lambda_{r}}\right)-\beta \ln \left(\frac{2 \lambda_{d}}{\kappa q \beta \gamma^{*}}\right)}{2(2-\alpha-\beta)}\right] \\
e_{d}^{*}=\exp \left[\frac{(\alpha-2) \ln \left(\frac{2 \lambda_{d}}{\kappa q \beta \gamma^{*}}\right)-\alpha \ln \left(\frac{2 \lambda_{r}}{\kappa q \alpha\left(1-\gamma^{*}\right)}\right)}{2(2-\alpha-\beta)}\right]
\end{gathered}
$$

The following equation is obtained by solving Eqs. (9) and (13) simultaneously:

$$
B^{*}=U-\gamma^{*} \kappa q e_{r}{ }^{\alpha} e_{d}^{* \beta}-\lambda_{d} e_{d} *^{2}=U-\frac{1}{2} \gamma^{*} e_{r}{ }^{\alpha} e_{d}^{* \beta}(2-\beta) \kappa q
$$




\section{MODEL ANALYSIS}

This section analyses the influence of exogenous variables on the contract parameters $\gamma$ and $B$.

The contract parameters $\gamma$ are analysed by: $\gamma^{*}=\frac{1}{1+\sqrt{\alpha(2-\beta) / \beta(2-\alpha)}}$.

Derivating the optimal revenue sharing coefficient $\gamma^{*}$ of $\alpha$ results in the following:

$$
\frac{\partial \gamma^{*}}{\partial \alpha}=-\frac{\alpha(2-\beta) /\left[\beta(2-\alpha)^{2}\right]+(2-\beta) /[\beta(2-\alpha)]}{2[1+\sqrt{\alpha(2-\beta) /[\beta(2-\alpha)]}]^{2} \sqrt{\alpha(2-\beta) /[\beta(2-\alpha)]}}
$$

Because $0<\alpha<1,0<\beta<1$, so: $\frac{\partial \gamma^{*}}{\partial \alpha}<0$.

Derivate the optimal revenue sharing coefficient $\gamma^{*}$ of $\beta$ results in the following:

$$
\frac{\partial \gamma^{*}}{\partial \beta}=\frac{\alpha /[\beta(2-\alpha)]+\alpha(2-\beta) /\left[\beta^{2}(2-\alpha)\right]}{2[1+\sqrt{\alpha(2-\beta) /[\beta(2-\alpha)]}]^{2} \sqrt{\alpha(2-\beta) /[\beta(2-\alpha)]}}
$$

Because $0<\alpha<1,0<\beta<1$, so: $\frac{\partial \gamma^{*}}{\partial \beta}>0$.

Then it is easy to arrive at conclusion 1 .

Conclusion 1. The optimal revenue sharing coefficient is negative correlation with the degree of the manufacturer's input effort in the development of the core component, and it is positive correlation to the degree of the supplier's input effort in the development of the supporting components. It is not affected by the fixed payment and the quality of product innovation.

Conclusion 1 suggests that when the impact on the success of product innovation of the manufacturer's input effort in the development of the core component is greater, the revenue sharing coefficient is smaller, and the supplier's incentive intensity is smaller. The reason is that the supplier's input effort's influence on the success of product innovation is very small, and the manufacturer does not need to share much product market revenue with the supplier. Conversely, the greater the supplier's input effort's impact on the success of innovative products, the revenue sharing coefficient is greater, because the supplier's development of supporting component is relatively important and the manufacturer needs to share more market revenue.

Meanwhile, conclusion 1 denotes that optimal revenue sharing coefficient does not consider the quality of product innovation and the fixed payment when the supply chain collaborates to develop products. This also means that the revenue sharing coefficient is only related to the relative importance of the supporting components no matter how much the manufacture gives a fixed payment to the supplier. If the supporting component is relative important, the supplier will request a higher share of the revenue.

In the next stage the contract parameter $B$ will be analysed. We substitute Eqs. (15) and (16) to Eq. (17) and eliminate $e_{r}^{*}, e_{d}^{*}$, then we can obtain the optimal fixed payment's expression as follows:

$$
B^{*}=U-\frac{1}{2} \gamma^{*} \kappa q(2-\beta) \exp \left[\begin{array}{l}
\frac{(2-\beta) \ln \left(\left(\alpha \kappa q\left(1-\gamma^{*}\right) / 2 \lambda_{r}\right)\right.}{2(2-\alpha-\beta)}+ \\
\frac{(\alpha-\beta-2) \ln \left(2 \lambda_{d} /\left(\beta \kappa q \gamma^{*}\right)\right)}{2(2-\alpha-\beta)}- \\
\frac{\alpha \ln \left(2 \lambda_{r} /\left(\alpha \kappa q\left(1-\gamma^{*}\right)\right)\right)}{2(2-\alpha-\beta)}
\end{array}\right]
$$


As the exponential function is positive and $0<\beta<1,2-\beta>0$, arrives at the result $B^{*}<U$. This result indicates that the manufacturer gives the supplier a fixed payment less than the supplier's reservation utility. The supplier cannot obtain the complete retention effect through the fixed payment, and the supplier must invest in the research and development efforts in the subsequent development of the necessary component.

We derivate the optimal fixed payment $B^{*}$ of $\lambda_{r}$ and we obtain the following result:

$$
\frac{\partial B^{*}}{\partial \lambda_{r}}=\frac{\gamma^{*} \kappa q(2-\beta)(2-\beta+\alpha)}{4 \lambda_{r}(2-\alpha-\beta)} \exp \left[\begin{array}{l}
\frac{(2-\beta) \ln \left(\alpha \kappa q\left(1-\gamma^{*}\right) / 2 \lambda_{r}\right)}{2(2-\alpha-\beta)}+ \\
\frac{(\alpha-\beta-2) \ln \left(2 \lambda_{d} /\left(\beta \kappa q \gamma^{*}\right)\right)}{2(2-\alpha-\beta)}- \\
\frac{\alpha \ln \left(2 \lambda_{r} /\left(\alpha \kappa q\left(1-\gamma^{*}\right)\right)\right)}{2(2-\alpha-\beta)}
\end{array}\right]
$$

Because the exponential function is positive and $0<\alpha<1,0<\beta<1,2-\beta>0$, so we arrive at: $\frac{\partial B^{*}}{\partial \lambda_{r}}>0$.

We derivate the optimal fixed payment $B^{*}$ of $\lambda_{d}$ and we obtain the following result:

$$
\frac{\partial B^{*}}{\partial \lambda_{d}}=\frac{\gamma^{*} \kappa q(2-\beta)(2-\alpha+\beta)}{4 \lambda_{d}(2-\alpha-\beta)} \exp \left[\begin{array}{l}
\frac{(2-\beta) \ln \left(\alpha \kappa q\left(1-\gamma^{*}\right) / 2 \lambda_{r}\right)}{2(2-\alpha-\beta)}+ \\
\frac{(\alpha-\beta-2) \ln \left(2 \lambda_{d} /\left(\beta \kappa q \gamma^{*}\right)\right)}{2(2-\alpha-\beta)}- \\
\frac{\alpha \ln \left(2 \lambda_{r} /\left(\alpha \kappa q\left(1-\gamma^{*}\right)\right)\right)}{2(2-\alpha-\beta)}
\end{array}\right]
$$

Because the exponential function is positive and $0<\alpha<1,0<\beta<1,2-\beta>0$, so we can get the result $\frac{\partial B^{*}}{\partial \lambda_{d}}>0$. result:

In the Eq. (20), we derivate optimal fixed payment $B^{*}$ of $q$ and we arrive at the following

$$
\frac{\partial B^{*}}{\partial q}=-\frac{\gamma^{*} \kappa(2-\beta)(4-\alpha-\beta)}{2(2-\alpha-\beta)} \exp \left[\begin{array}{l}
\frac{(2-\beta) \ln \left(\left(\alpha \kappa q\left(1-\gamma^{*}\right) / 2 \lambda_{r}\right)\right.}{2(2-\alpha-\beta)}+ \\
\frac{(\alpha-\beta-2) \ln \left(2 \lambda_{d} /\left(\beta \kappa q \gamma^{*}\right)\right)}{2(2-\alpha-\beta)}- \\
\frac{\alpha \ln \left(2 \lambda_{r} /\left(\alpha \kappa q\left(1-\gamma^{*}\right)\right)\right)}{2(2-\alpha-\beta)}
\end{array}\right]
$$

Because the exponential function is positive and $0<\alpha<1,0<\beta<1,2-\beta>0$, $4-\alpha-\beta>0$, so we can get the result $\frac{\partial B^{*}}{\partial q}<0$.

From Eqs. (21), (22), (23) yields the following conclusion:

Conclusion 2: the optimal fix payment $B^{*}$ is a positive correlation with the manufacturer's and the supplier's cost coefficient, and it is negative correlation with the product innovation quality.

Conclusion 2 means that when the cost of the supplier's development of supporting component is increasing, the manufacturer must pay a higher amount of fixed payment to encourage the supplier in order to make up for the cost to the supplier. 
When the manufacturer's development cost of the core component is increasing, the manufacturer must pay a larger fixed payment as an incentive to the supplier. This is because we can know that the manufacturer's increasing cost cannot influence the revenue sharing factor from conclusion 1, so the manufacturer's expected revenue will decrease and it will reduce the effort to develop core component. This will reduce the likelihood of successful product innovation; the manufacturer must increase the amount of the fixed payment to attract the supplier to be involved in developing supporting component.

Meanwhile, the more fixed payments the manufacturer gives to the supplier, the lower the quality of the product innovation. This is because the market revenue sharing coefficient obtained by the supplier to develop the product is only related to the relative importance of the development of the supporting components and it is irrelevant to the fixed payment from conclusion 1. Therefore, the manufacturer's increasing fixed payment means that the supplier need not put too much input effort into developing supporting component and it also can get a larger stable revenue, and the supplier may have "lazy" motivation because of the high fixed payment.

\section{DIGITAL SIMULATION}

In order to verify conclusion 1 , we calculate the optimal revenue sharing coefficient $\gamma^{*}$ on different combinations of $\alpha, \beta$. We use MATLAB to map according Eq. (14) $\gamma^{*}=\frac{1}{1+\sqrt{\alpha(2-\beta) / \beta(2-\alpha)}}$ and obtain Fig. 1. From Fig. 1 we can see that the optimal revenue sharing coefficient is negative correlation with the importance of the manufacturer's developing core component, and the optimal revenue sharing coefficient is positive correlation with the importance of the supplier's developing supporting component. Thus, conclusion 1 is verified.

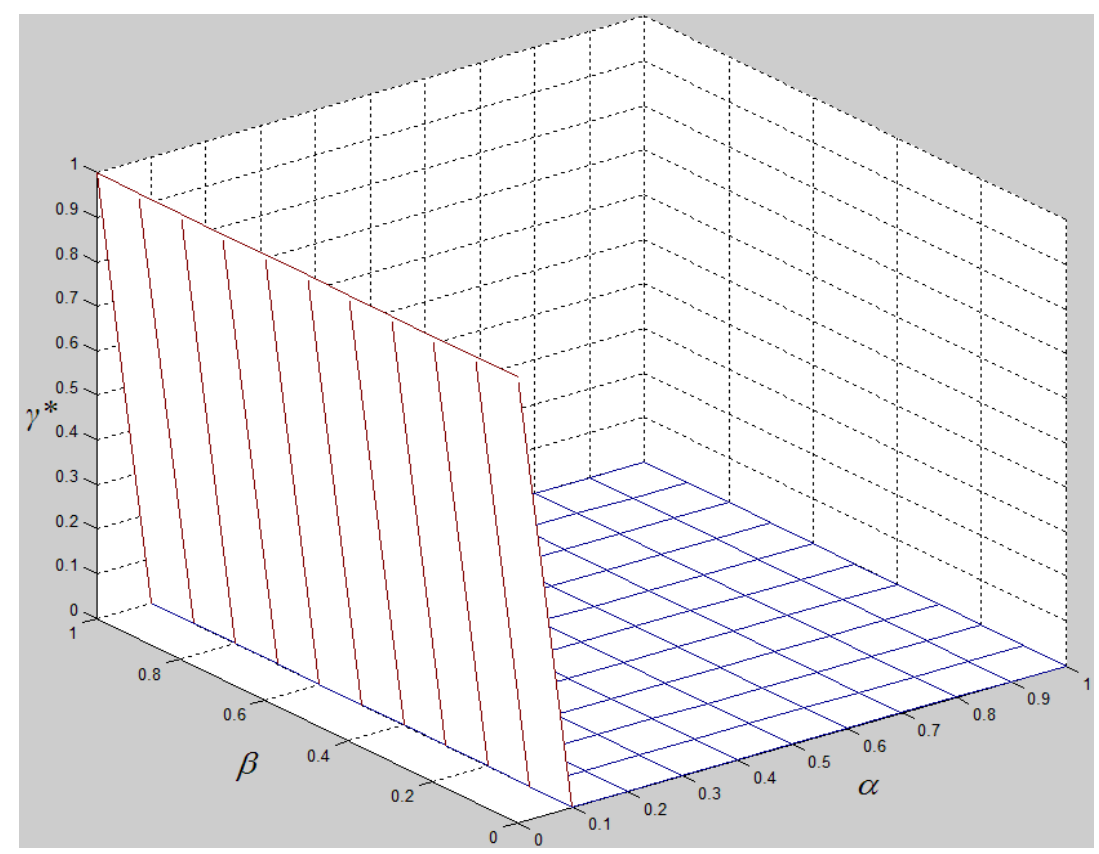

Figure 1: The importance of developing components' influence on revenue sharing coefficient.

In order to verify the effect of the manufacturer's and the supplier's cost coefficient's influence on the optimal fixed payment, we assume $\kappa=8, q=0.5, U=4, \alpha=0.5, \beta=0.5$, $\lambda_{r}, \lambda_{d} \in[1,5]$, and use MATLAB to map according to Eq. (20) arriving at Fig. 2. From Fig. 2 
we can see that the optimal fix payment $B^{*}$ is positive correlation with the manufacturer's and supplier's cost coefficient $\lambda_{r}, \lambda_{d}$.

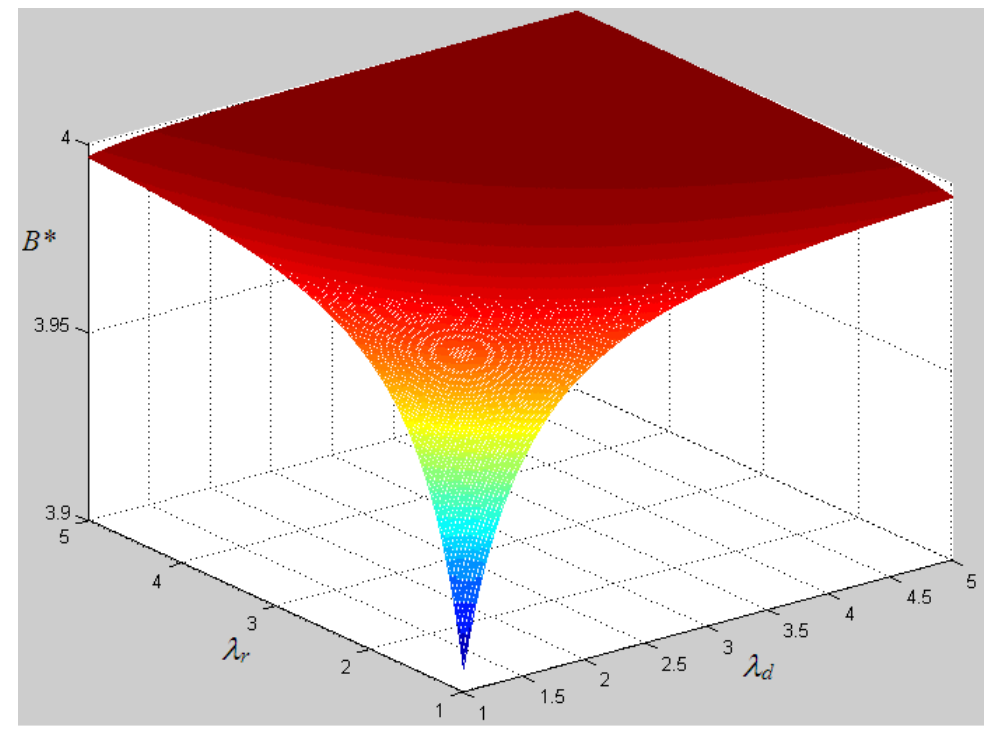

Figure 2: Cost coefficient's influence on the optimal fixed payment.

In order to verify the effect of fixed payment's influence on the quality of product innovation, we assume $\kappa=8, U=4, \alpha=0.5, \beta=0.5, \lambda_{r}=1, \lambda_{d}=1$, we use MATLAB to map according to Eq. (20) and we can get Fig. 3. From Fig. 3 we can see that the optimal fix payment $B^{*}$ is negative correlation with the quality of product innovation $q$.

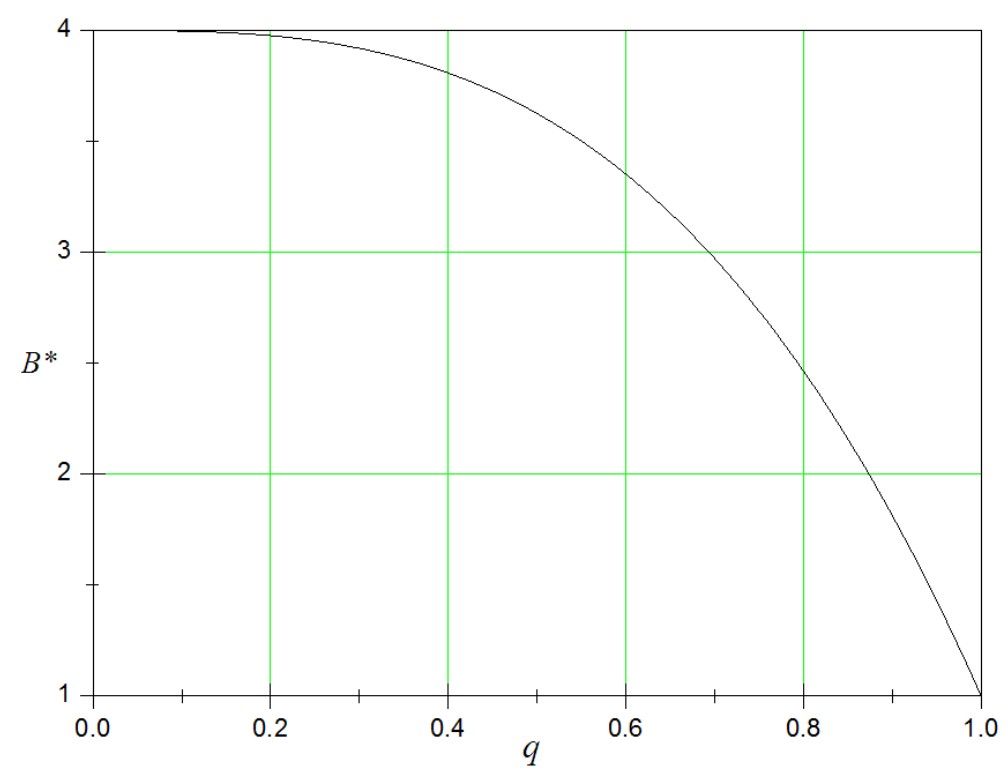

Figure 3: Fixed payment's influence on the quality of product innovation.

\section{CONCLUSION}

This paper researches the contract design under the condition that the manufacturer develops the core components and supplier develops the supporting component in a collaborative manner in the supply chain. In order to avoid the possibility of supplier's corrupt behaviour, it is necessary to consider the impact on market revenue, which is caused by product innovation quality. Specifically, the manufacturer not only offers the supplier a certain amount of fixed 
payment, but also shares market revenue of the product with the supplier in the contract design. The research shows: (1) The optimal revenue sharing coefficient has a negative correlation with the impacting coefficient of product innovation success, which is affected by the efforts put into core components development by the manufacturers. The optimal revenue sharing coefficient has a positive correlation with the impacting coefficient of product innovation success, which is affected by the efforts put into development of supporting component by the suppliers. The optimal revenue sharing coefficient has no correlation with the fixed payment and innovation quality of products. (2) The optimal fixed payment has a positive correlation with the cost coefficient of developing the core components and supporting components by both sides in the supply chain, and it has negative correlation with the quality of innovation of products.

\section{ACKNOWLEDGMENT}

This work was supported by National Natural Science Funds of China (Grant nos. 71561009, 71571126, 71303271, 71301065), Humanities and Social Sciences Youth Foundation of Chinese Ministry of Education (Grant no. 12YJC630234, 13YJC630246, 13YJC630166), National Social Science Foundation of China (Grant No. 15BGL010), Youth Science and Technology Talents Project of Chongqing (Grant No. cstc2014kjrc-qnrc00003).

\section{REFERENCES}

[1] Buehler, S.; Haucap, J. (2006). Strategic outsourcing revisited, Journal of Economic Behavior \& Organization, Vol. 61, No. 3, 325-338, doi:10.1016/j.jebo.2004.11.008

[2] Belcourt, M. (2006). Outsourcing - The benefits and the risks, Human Resource Management Review, Vol. 16, No. 2, 269-279, doi:10.1016/j.hrmr.2006.03.011

[3] Alshawi, S.; Saez-Pujol, I., Irani, Z. (2003). Data warehousing in decision support for pharmaceutical R\&D supply chain, International Journal of Information Management, Vol. 23, No. 3, 259-268, doi:10.1016/S0268-4012(03)00028-8

[4] Milliou, C. (2004). Vertical integration and R\&D information flow: is there a need for 'firewalls'?, International Journal of Industrial Organization, Vol. 22, No. 1, 25-43, doi:10.1016/S0167-7187(03)00090-0

[5] Morgan, J. M.; Liker, J. K. (2006). The Toyota Product Development System: Integrating People, Process, and Technology, Productivity Press, New York

[6] Olausson, D.; Magnusson, T.; Lakemond, N. (2009). Preserving the link between R\&D and manufacturing: Exploring challenges related to vertical integration and product/process newness, Journal of Purchasing and Supply Management, Vol. 15, No. 2, 79-88, doi:10.1016/ j.pursup.2008.12.004

[7] Tsai, C.-F. (2006). An intelligent adaptive system for the optimal variable selections of R\&D and quality supply chains, Expert Systems with Applications, Vol. 31, No. 4, 808-825, doi:10.1016/ j.eswa.2006.01.006

[8] Rokuhara, A. (1985). $R \& D$ and Antimonopoly Policy (in Japanese), Gyosei, Tokyo

[9] Harabi, N. (2002). The impact of vertical R\&D cooperation on firm innovation: An empirical investigation, Economics of Innovation and New Technology, Vol. 11, No. 2, 93-108, doi: $10.1080 / 10438590210900$

[10] Licht, G.; Zoz, K. (2000). Patents and R\&D: An econometric investigation using applications for German, European and US patents by German companies, Encaoua, D.; Hall, B. H.; Laisney, F.; Mairesse, J. (Eds.), The Economics and Econometrics of Innovation, Kluwer Academic Publishers, Boston, 307-338

[11] Mikkola, J. H.; Skjoett-Larsen, T. (2003). Early supplier involvement: Implications for new product development outsourcing and supplier-buyer interdependence, Global Journal of Flexible Systems Management, Vol. 4, No. 4, 31-41 
[12] Atallah, G. (2002). Vertical R\&D spillovers, cooperation, market structure, and innovation, Economics of Innovation and New Technology, Vol. 11, No. 3, 179-209, doi:10.1080/ 10438590210903

[13] Petersen, K. J.; Handfield, R. B.; Ragatz, G. L. (2003). A model of supplier integration into new product development, Journal of Product Innovation Management, Vol. 20, No. 4, 284-299, doi:10.1111/1540-5885.00028

[14] Gilbert, S. M.; Cvsa, V. (2003). Strategic commitment to price to stimulate downstream innovation in a supply chain, European Journal of Operational Research, Vol. 150, No. 3, 617-639, doi:10.1016/S0377-2217(02)00590-8

[15] Van Echtelt, F. E. A.; Wynstra, F.; Van Weele, A. J.; Duysters, G. (2008). Managing supplier involvement in new product development: A multiple-case study, Journal of Product Innovation Management, Vol. 25, No. 2, 180-201, doi:10.1111/j.1540-5885.2008.00293.x

[16] Lakemond, N.; Berggren, C.; van Weele, A. (2006). Coordinating supplier involvement in product development projects: a differentiated coordination typology, $R \& D$ Management, Vol. 36, No. 1, 55-66, doi:10.1111/j.1467-9310.2005.00415.x

[17] Çanakoğlu, E.; Bilgic, T. (2007). Analysis of a two-stage telecommunication supply chain with technology dependent demand, European Journal of Operational Research, Vol. 177, No. 2, 995-1012, doi:10.1016/j.ejor.2006.01.006

[18] Jean, R.-J. B.; Sinkovics, R. R.; Hiebaum, T. P. (2014). The effects of supplier involvement and knowledge protection on product innovation in customer-supplier relationships: A study of global automotive suppliers in China, Journal of Product Innovation Management, Vol. 31, No. 1, 98-113, doi:10.1111/jpim.12082

[19] Kim, K. K.; Lim, M. K. (2015). R\&D outsourcing in an innovation-driven supply chain, Operations Research Letters, Vol. 43, No. 1, 20-25, doi:10.1016/j.orl.2014.10.005

[20] Wang, J.; Shin, H. (2015). The impact of contracts and competition on upstream innovation in a supply chain, Production and Operations Management, Vol. 24, No. 1, 134-146, doi: $\underline{10.1111 / \text { poms. } 12218}$ 